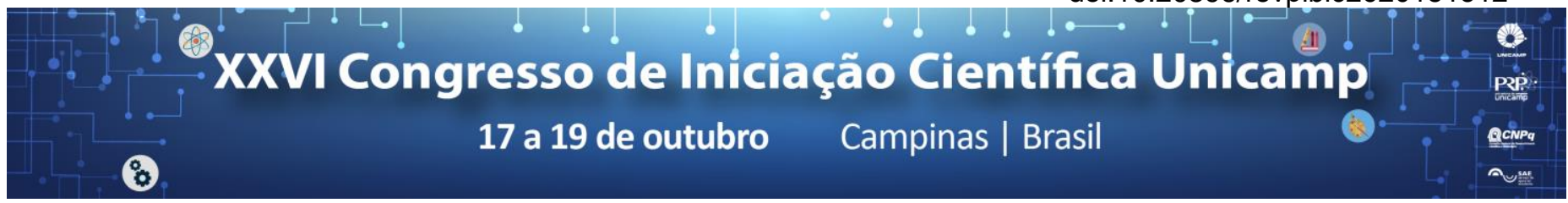

\title{
Análise de segunda ordem com influência das imperfeições geométricas iniciais em pórticos planos de aço.
}

\section{Thatiane Mitie Nogi ${ }^{\star}$ Bruno Eizo Higaki.}

\section{Resumo}

O objetivo deste trabalho é analisar a influência das imperfeições geométricas iniciais na estabilidade de pórticos planos de aço. Para isto serão realizadas e comparadas metodologias de análises distintas via método dos elementos finitos considerando a estrutura sem imperfeições geométricas iniciais, com a presença de imperfeições geométricas iniciais por meio da aplicação de forças nocionais e modelagem dos nós da estrutura em uma posição deslocada inicialmente, e pela análise de segunda ordem simplificada por meio do método B1-B2 proposto pela NBR8800:2008.

\section{Palavras-chave:}

Análise estrutural, Imperfeições geométricas iniciais, pórticos planos de aço.

\section{Introdução}

A análise estrutural determina como a estrutura reage quanto a esforços internos e deslocamentos quando submetida aos esforços atuantes. A NBR8800:2008 recomenda o tipo de análise a ser utilizado para cada estrutura conforme o seu grau de deslocabilidade.

A análise estrutural pode ser dividida quanto a estabilidade da estrutura, análise linear (1 ${ }^{\underline{a}}$ ordem) ou não-linear ( $2^{\mathrm{a}}$ ordem) e quanto ao comportamento do material, elástica ou inelástica.

Visando se aproximar das condições reais da estrutura são consideradas as imperfeições geométricas iniciais, que podem ser classificadas como global, quando há um desaprumo e como local, quando a peça apresenta uma curvatura na barra.

Essas imperfeições podem ser consideradas com a utilização de forças nocionais que reproduzem os efeitos equivalentes das imperfeições geométricas iniciais e com a modelagem da estrutura pelo método dos nós deslocados.

Este trabalho compara diversos métodos de análises para estudar a influência das imperfeições geométricas iniciais. As análises estruturais deste estudo consideram as imperfeições do material.

\section{Resultados e Discussão}

O pórtico estudado neste trabalho está ilustrado na Figura 1.

Figura 1. Pórtico.

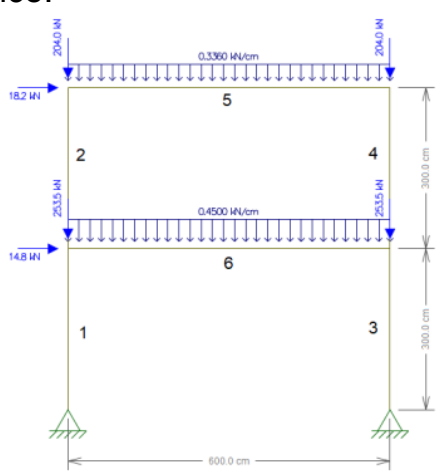

As vigas (barras 5 e 6) apresentam perfil do aço igual a w250x73, enquanto os pilares (barras 1,2,3 e 4) tem perfil igual a w360x72.
A Tabela 1 apresenta a classificação da estrutura quanto a deslocabilidade, conforme a consideração da NBR8800:2008 e as diferenças percentuais dos métodos de análises utilizados no ponto mais solicitado da estrutura.

Tabela 1. Diferenças percentuais dos métodos utilizados.

\begin{tabular}{|c|c|c|c|}
\hline \multirow{2}{*}{$\begin{array}{c}\text { Classificação } \\
\text { da estrutura }\end{array}$} & \multicolumn{3}{|c|}{ Diferença [\%] } \\
\cline { 2 - 4 } & $\mathrm{A} / \mathrm{D}$ & $\mathrm{B} / \mathrm{D}$ & $\mathrm{C} / \mathrm{D}$ \\
\hline $\begin{array}{c}\text { Média } \\
\text { deslocabilidade }\end{array}$ & $-7,33$ & $-8,75$ & $-1,38$ \\
\hline
\end{tabular}

Onde:

A - Análise de segunda ordem;

B - Análise de segunda ordem, considerando forças nocionais;

C - Análise de segunda ordem pelos coeficientes amplificadores B1 e B2;

D - Análise de segunda ordem considerando deslocamentos dos nós para modelagem da estrutura.

Todos os métodos foram comparados com a análise $D$, por essa apresentar resultados que condiz mais com a realidade.

\section{Conclusões}

De acordo com os resultados obtidos, percebe-se que as diferenças entre os métodos são pequenas, o que condiz com a recomendação da NBR8800:2008, que recomenda para estruturas de média deslocabilidade a análise de $2^{\mathrm{a}}$ ordem elástico, não sendo necessário uma análise mais rigorosa.

\section{Agradecimentos}

Ao Centro Universitário $\mathrm{FEl}$ que tornou possível a realização desse trabalho.
${ }^{1}$ ASSOCIAÇÃO BRASILEIRA DE NORMAS TÉCNICAS. NBR 8800:
execução de estruturas de aço de edifícios. Rio de Janeiro, set. 2008.

2 SOUZA, A.S.C. Análise da estabilidade de edifícios de andares múltiplos em aço. 2009. 116 f. Iniciação científica - Universidade Federal de São Carlos, São Carlos, 2009. 